\title{
Revestimento de Níquel Depositado pela Soldagem MIG e MIG com Arame Frio
}

Carlos Alberto Mendes da Mota ${ }^{1}$, Alexandre Saldanha do Nascimento ${ }^{1}$, Douglas Neves Garcia ${ }^{1}$, Diego Almir Silva da Silva ${ }^{1}$, Felipe Ribeiro Teixeira ${ }^{1}$, Valtair Antonio Ferraresi ${ }^{2}$

1 Universidade Federal do Pará - UFPA, Faculdade de Engenharia Mecânica, Programa de Pós-graduação em Engenharia Mecânica - PPGEM, Belém, PA, Brasil.

2 Universidade Federal de Uberlândia - UFU, Faculdade de Engenharia Mecânica, Programa de Pós-graduação em Engenharia Mecânica - PPGEM, Uberlândia, MG, Brasil.

Recebido: 28 Maio, 2016

Aceito: 21 Nov., 2016

E-mail: cmota@ufpa.br (CAMM)
Este é um artigo publicado em acesso aberto (Open Access) sob a licença Creative Commons Attribution Non-Commercial, que permite uso, distribuição e reprodução em qualquer meio, sem restriçōes desde que sem fins comerciais e que 0 trabalho original seja corretamente citado.
Resumo: Este artigo apresenta um estudo das características operacionais, geométricas e microestruturais de soldas MIG e MIGAF (MIG com arame frio) aplicadas no revestimento de chapa de um aço AISI 1020, com uma superliga de níquel ER NiCrMo-4, tipo Hastelloy 276 C. A soldagem foi automatizada, na posição plana, e realizada por uma fonte eletrônica em CC+ com aquisição instantânea dos oscilogramas de corrente e tensão de soldagem. As variáveis de entrada foram às velocidades do arame eletrodo e do arame frio, e a velocidade de soldagem. Foram avaliadas a operacionalidade dos processos e o efeito da energia de soldagem sobre as características geométricas (reforço e largura), diluição, microestrutura e microdureza do revestimento. Os resultados indicaram um bom desempenho operacional, a ausência de defeitos nos passes isolados e nos revestimentos para as soldagens com MIGAF. Além disso, constataram-se menores níveis de diluição.

Palavras-chave: Superligas de níquel; Hastelloy 276C; Soldagem dissimilar; Revestimento.

\section{Coating Welds with a Nickel Superalloy Deposited by GMAW and GMAW Cold Wire}

\begin{abstract}
This paper presents a study about the operational, geometrical and microstructural characteristics of GMAW and GMAW-CW (GMAW Cold Wire) welds applied on a coating of steel AISI 1020 plate, with a nickel superalloy ER NiCrMo-4, Hastelloy 276C type. The welding was automated in flat position, and executed with an electronic source on DC+ and having instantaneous acquisition of the welding voltage and current oscillograms. The input variables were the speeds of the electrode and cold wires and the welding speed. It was evaluated the operational processes and the effect of heat input on the geometrical characteristics (reinforcement and width), dilution, microstructure and microhardness of the coating. The results indicated a good operating performance, the absence of defects in single passes and in the GMAW-CW coatings. Furthermore, it has been found the lowest level of dilution.
\end{abstract}

Key-words: Nickel superalloys; Hastelloy 276C; Dissimilar welding; Coating welding.

\section{Introdução}

A degradação corrosiva em superfícies de equipamentos é um dos principais problemas das indústrias de petróleo e gás natural. Ocorre principalmente devido à contaminação por materiais corrosivos e/ou abrasivos que afetam às linhas de destilação e processamento de petróleo, derivados e gás natural [1-7]. Pode ocorrer pela ação isolada ou combinada da erosão, da corrosão e/ou do atrito com influências da temperatura, da composição química e das características de resistência do material na superfície em exposição. A aplicação de camadas de revestimento por materiais especiais e resistentes a corrosão se constitui numa ação preventiva para se reduzir a degradação estrutural de equipamentos e de seus componentes [6-10]. Para muitas aplicações é vantajoso construir a estrutura em aço carbono e revesti-la com um material mais nobre e resistente à degradação superficial. Para este tipo de arranjo são determinantes o baixo custo, as favoráveis características de transformação e de resistência mecânica do aço carbono na fabricação de estruturas pesadas, somadas às excelentes e superiores características de resistências a corrosão e a oxidação dos materiais especiais usados para revestir superfícies [1,3,5,6,11-13]. As superligas de níquel têm sido usadas com frequência no revestimento de superfícies para a proteção de substratos estruturais edificados, por exemplo, em aço carbono, com vistas a aumentar a vida útil do equipamento, reduzir custos e minimizar intervenções em manutenção 
não programada. Além disso, a sua excelente soldabilidade potencializa a deposição de soldas robustas e livres de defeitos, os quais, se presentes, podem causar danos, a ruptura ou até o colapso da estrutura com risco de acidentes catastróficos por explosões e/ou vazamento de produtos tóxicos armazenados ou transportados.

Para o revestimento em grandes áreas superficiais a soldagem MIG tem sido uma das mais utilizadas pela sua elevada produtividade, facilidade de operação, mecanização e acessibilidade. A soldagem MIGAF é uma técnica derivativa do processo MIG que apresenta, além das vantagens deste, uma maior produtividade, menor diluição e um grande potencial para utilização no campo. Na soldagem MIGAF, Figura 1 [11], um arame frio (não energizado) posicionado à frente do arame eletrodo é alinhado à direção de soldagem e injetado, com velocidade controlada, na poça de fusão. O objetivo da técnica de soldagem MIGAF é aproveitar a energia e a estabilidade do arco voltaico de uma dada condição ou procedimento aprovado da soldagem MIG, sem causar perturbação significativa à estabilidade do processo, aos movimentos convectivos na poça fusão e/ou a qualidade da solda [11,14-17]. A soldagem MIGAF é estudada desde 2005 pelo grupo de estudos em tecnologia da soldagem/FEM/ITEC/UFPA, tendo sido alcançados avanços no entendimento operacional, comportamento metalúrgico e em sua viabilidade para aplicações práticas [6,11,14-19].

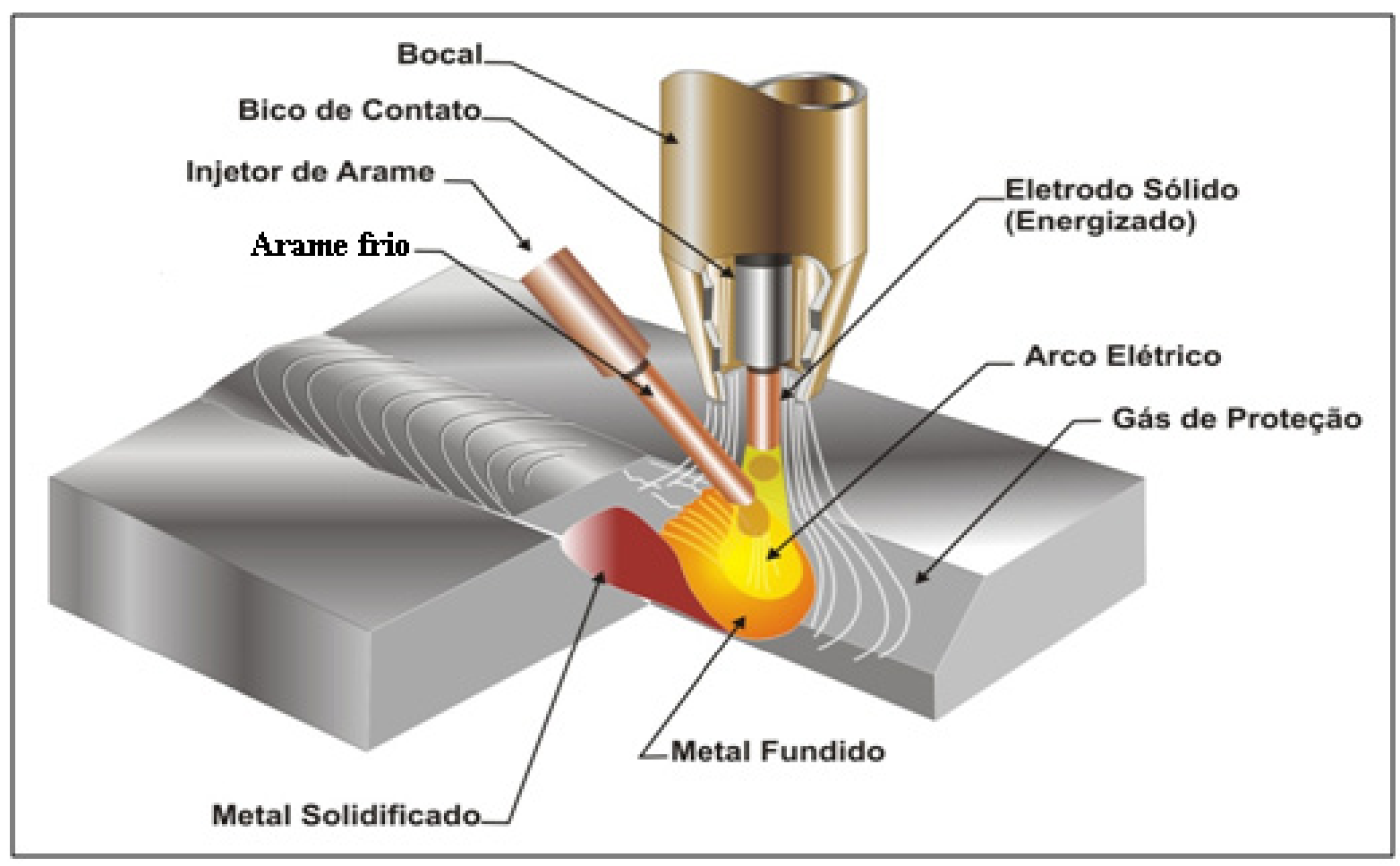

Figura 1. Esquema da tocha e da entrada do arame frio na soldagem MIGAF.

Este trabalho apresenta um estudo do comportamento operacional das soldagens MIG e MIGAF, e das características geométricas e microestruturais de soldas depositadas por uma superliga de níquel, ER NiCrMo-4, sobre chapas de aço carbono.

\section{Procedimentos Experimentais}

\subsection{Equipamentos e acessórios}

As soldagens MIG e MIGAF foram realizadas na posição plana com o auxílio de uma bancada automatizada de trabalho composta por uma fonte eletrônica ajustada em $\mathrm{CC}^{+}$, um dispositivo de posicionamento e movimentação mecanizada da tocha, um sistema de aquisição dos oscilogramas para o monitoramento dos dados instatâneos 
da corrente e da tensão de soldagem, e um sistema auxiliar para alimentação do arame frio. Foram usados ainda equipamentos e instrumentos para os ensaios metalográficos e de microdureza. Além de programas computacionais específicos de tratamento e processamento de dados.

\subsection{Materiais}

As soldas foram depositadas por uma liga de níquel da classe AWS ER NiCrMo-4 na forma de arame com diâmetro 1,2 mm. Como metal de base foi usado um aço estrutural AISI 1020, na forma de chapa medindo $150 \mathrm{~mm}$ x $75 \mathrm{~mm}$ x 6,4 mm. O argônio puro foi usado como gás de proteção, numa vazão de $15 \mathrm{l} / \mathrm{min}$. A Tabela 1 apresenta a composição química do metal de adição e do metal de base.

Tabela 1. Composição química do metal de adição e do metal de base.

\begin{tabular}{|c|c|c|c|c|c|c|c|}
\hline \multirow[t]{2}{*}{ Materiais } & \multicolumn{7}{|c|}{ Composição química em peso (\%) } \\
\hline & $\mathrm{Ni}$ & $\mathrm{Cr}$ & Mo & V & W & $\mathrm{Cu}$ & Co \\
\hline \multirow{3}{*}{$\begin{array}{l}\text { Liga } \\
\text { AWS ERNiCrMo-4 } \\
\text { Hastelloy } 276 \mathrm{C}\end{array}$} & Bal & $14,5-16,5$ & $15-17$ & $0,35^{*}$ & $3-4,5$ & $0,5^{*}$ & $2,5^{*}$ \\
\hline & $\mathrm{C}$ & $\mathrm{Fe}$ & $\mathrm{Mn}$ & $\mathrm{Si}$ & $\mathrm{P}$ & $S$ & Outros \\
\hline & $0,02 *$ & $4,0-7,0$ & $1,0^{*}$ & $0,08^{*}$ & $0,04^{*}$ & $0,03^{*}$ & $0,5^{*}$ \\
\hline \multirow{2}{*}{$\begin{array}{l}\text { Aço } \\
\text { AISI } 1020\end{array}$} & C & \multicolumn{2}{|c|}{$\mathrm{Mn}$} & \multicolumn{2}{|c|}{$\mathrm{P}$} & \multicolumn{2}{|c|}{$\mathrm{S}$} \\
\hline & $0,18-0,23$ & \multicolumn{2}{|c|}{$0,30-0,60$} & \multicolumn{2}{|c|}{$0,040^{*}$} & \multicolumn{2}{|c|}{$0,050^{*}$} \\
\hline
\end{tabular}

*Valores máximos.

\subsection{Métodos}

Inicialmente foi realizada a soldagem de passes isolados em simples deposição com três repetições, visando avaliar o comportamento operacional do processo, e o efeito da energia de soldagem sobre as características geométricas (reforço e relação reforço/largura) e sobre a diluição.

A Tabela 2 apresenta a matriz operacional com as condições de soldagem utilizadas, as quais foram obtidas a partir de ensaios exploratórios realizados em trabalhos anteriores [17]. Os parâmetros variáveis foram a energia

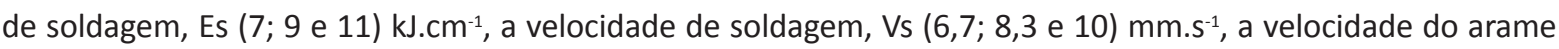
eletrodo, Ve (150; 167 e 183) $\mathrm{mm}^{-\mathrm{s}^{-1}}$ e a velocidade do arame frio, Vf (25; 40 e 55) \% Ve mm. $\mathrm{s}^{-1}$. Na nomenclatura MIG.XY.AF.N adotada para as soldas MIGAF, as letras XY indicam o valor percentual médio da velocidade de arame frio, ou seja, $25 \%, 40 \%$ e $55 \%$ da velocidade do arame eletrodo. A Tabela 2 apresenta na coluna Vf os valores reais, obtidos dos ensaios, e os percentuais entre parênteses. A letra N, variando de 1 a 9, indica uma condição de soldagem.

Para o cálculo da taxa de deposição (K) por unidade de comprimento de solda foi utilizada a Equação 1 , onde Va e Vs são, respectivamente, as velocidades de arame e de soldagem. Para a soldagem MIGAF, Va = Ve + Vf.

$$
K=\frac{V a}{V S}
$$

Para atender a requisitos pré-estabelecidos (projeto encomendado) e aplicação em soldas de revestimento foram adotados os seguintes critérios geométricos de aceitação para os passes isolados: reforço, $\mathrm{R} \geq 4 \mathrm{~mm}$, diluição ( $D \leq 10 \%)$, razão reforço/largura ( $R / L \leq 50 \%)$ e ausência de defeitos.

Para a realização da soldagem de revestimento foram utilizadas condições selecionadas da soldagem de passes isolados, observados os critérios de aceitação já estabelecidos. Os revestimentos foram depositados com quatro passes consecutivos (P1, P2, P3 e P4) em sobreposição lateral de $30 \%$, para se avaliar a qualidade, a microestrutura e a microdureza das amostras. 
Tabela 2. Resultado da soldagem de passes isolados. Técnicas de soldagem MIG e MIGAF.

\begin{tabular}{|c|c|c|c|c|c|c|c|c|}
\hline Soldagem & $\begin{array}{c}\text { Es } \\
\left(\mathrm{kJ} . \mathrm{cm}^{-1}\right)\end{array}$ & $\begin{array}{c}\text { Vs } \\
\left(\mathrm{mm} \cdot \mathrm{s}^{-1}\right)\end{array}$ & $\begin{array}{c}\text { Ve } \\
\left(\mathrm{mm} \cdot \mathrm{s}^{-1}\right)\end{array}$ & $\begin{array}{c}\text { Vf } \\
\left(\mathrm{mm} \cdot \mathrm{s}^{-1}\right)\end{array}$ & K & $\begin{array}{c}R \\
(\mathrm{~mm})\end{array}$ & $R / L$ & D (\%) \\
\hline MIG1 & 11 & 6,7 & 150 & 0 & 22,4 & 3,8 & 0,45 & 22 \\
\hline MIG2 & 9 & 8,3 & 150 & 0 & 18,0 & 3,3 & 0,44 & 26 \\
\hline MIG3 & 7 & 10 & 150 & 0 & 15,0 & 3,0 & 0,44 & 22 \\
\hline MIG4 & 11 & 6,7 & 167 & 0 & 24,9 & 3,9 & 0,41 & 26 \\
\hline MIG5 & 9 & 8,3 & 167 & 0 & 20,1 & 3,4 & 0,44 & 25 \\
\hline MIG6 & 7 & 10 & 167 & 0 & 16,7 & 3,2 & 0,43 & 20 \\
\hline MIG7 & 11 & 6,7 & 183 & 0 & 23,7 & 4,1 & 0,42 & 24 \\
\hline MIG8 & 9 & 8,3 & 183 & 0 & 22,0 & 3,6 & 0,40 & 20 \\
\hline MIG9 & 7 & 10 & 183 & 0 & 18,3 & 3,3 & 0,39 & 20 \\
\hline MIG25AF1 & 11 & 6,7 & 150 & 42 & 28,6 & 4,2 & 0,45 & 13 \\
\hline MIG25AF2 & 9 & 8,3 & 150 & 42 & 23,1 & 4,0 & 0,46 & 12 \\
\hline MIG25AF3 & 7 & 10 & 150 & $42(28 \% V e)$ & 19,2 & 3,7 & 0,45 & 12 \\
\hline MIG40AF3 & 7 & 10 & 150 & $58(38 \% \mathrm{Ve})$ & 20,8 & 3,9 & 0,48 & 10 \\
\hline MIG55AF3 & 7 & 10 & 150 & $83(55 \% \mathrm{Ve})$ & 23,3 & 4,1 & 0,52 & 9 \\
\hline MIG25AF4 & 11 & 6,7 & 167 & 42 & 31,2 & 4,3 & 0,44 & 14 \\
\hline MIG25AF5 & 9 & 8,3 & 167 & 42 & 25,2 & 4,1 & 0,46 & 13 \\
\hline MIG25AF6 & 7 & 10 & 167 & $42(25 \% \mathrm{Ve})$ & 20,9 & 3,9 & 0,46 & 11 \\
\hline MIG40AF6 & 7 & 10 & 167 & 67(40\%Ve) & 23,4 & 4,1 & 0,49 & 10 \\
\hline MIG55AF6 & 7 & 10 & 167 & $92(55 \% \mathrm{Ve})$ & 25,9 & 4,3 & 0,52 & 7 \\
\hline MIG25AF7 & 11 & 6,7 & 183 & 50 & 34,8 & 4,6 & 0,43 & 7 \\
\hline MIG25AF8 & 9 & 8,3 & 183 & 50 & 28,0 & 4,2 & 0,44 & 14 \\
\hline MIG25AF9 & 7 & 10 & 183 & $50(27 \%$ Ve) & 23,3 & 4,0 & 0,44 & 12 \\
\hline MIG40AF9 & 7 & 10 & 183 & 75(41\%Ve) & 25,8 & 4,2 & 047 & 10 \\
\hline MIG55AF9 & 7 & 10 & 183 & $100(55 \% \mathrm{Ve})$ & 28,3 & 4,3 & 0,51 & 7 \\
\hline
\end{tabular}

Após a soldagem, as amostras soldadas foram inspecionadas visualmente e, a seguir, seccionadas em três seções transversais de interesse para a preparação metalográfica convencional, específica para possibilitar as análises de macrografias, de micrografias ótica e eletrônica de varredura, além de microdureza. As Figuras 2 e 3 mostram, respectivamente, os esquemas do corte na solda e da preparação de amostras na seção transversal dos

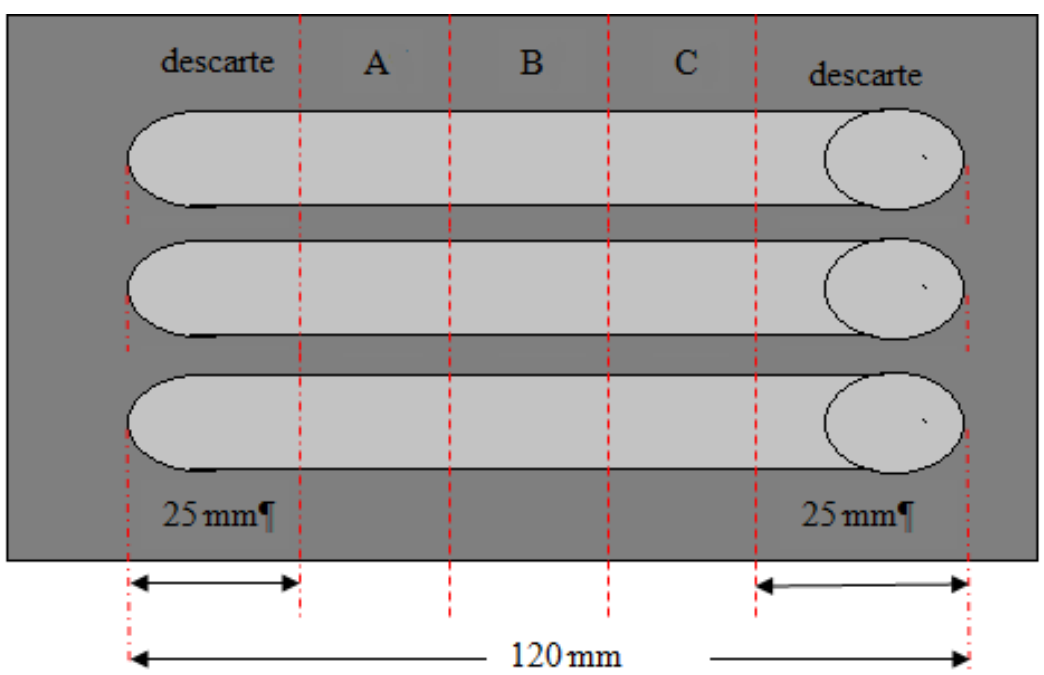

Figura 2. Corte das amostras dos passes isolados. 
passes isolados. Onde: $\mathrm{L}=$ largura; $\mathrm{R}=$ reforço; $\mathrm{P}=$ penetração; $\mathrm{ZF}=$ zona de fusão e $\mathrm{ZR}$ = zona de reforço. $\mathrm{A}$ Figura 4 apresenta um esquema da seção transversal do revestimento com quatro passes (P1, P2, P3 e P4) e mostra as regiões de interesse, para análises de macroestrutura, de microestrutura, e de microdureza.

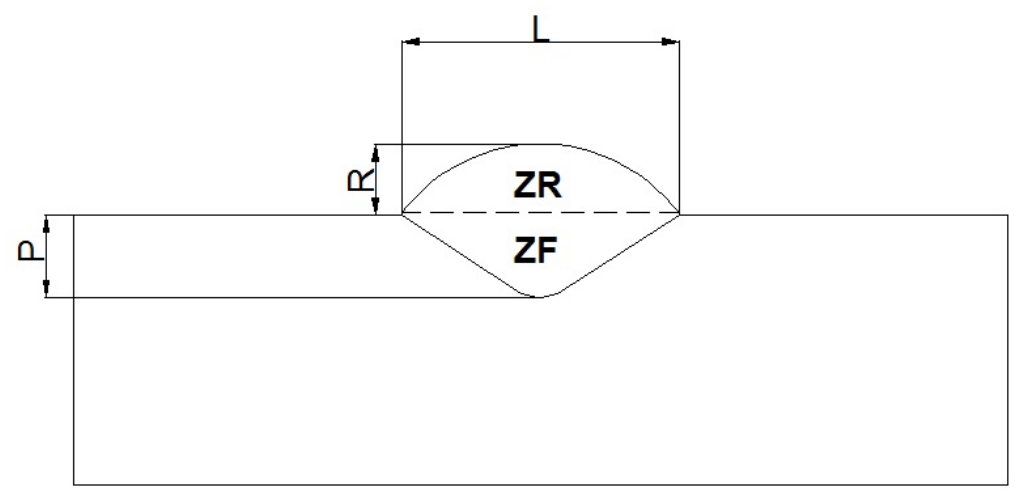

Figura 3. Seção transversal dos passes isolados.

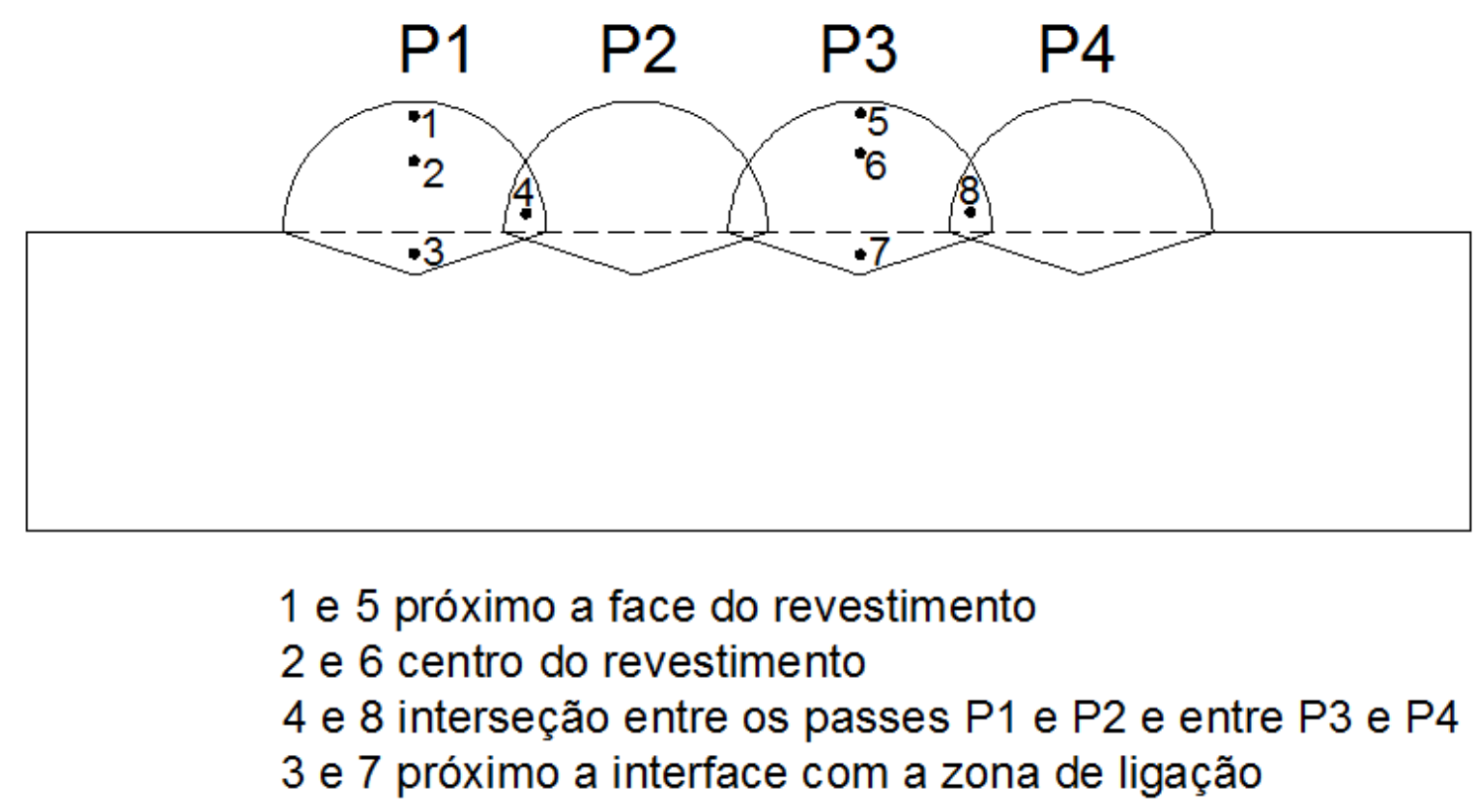

Figura 4. Zonas de análises microestrutural e microdureza do revestimento.

Para o ensaio macrográfico as superfícies transversais das amostras foram preparadas com lixas de 100 e 600 mesh e, posteriormente, atacadas com uma solução de Nital 3\% (3\% $\mathrm{HNO}_{3}$ e 97\% álcool etilíco), por 30 s. Para a análise de micrografia as amostras foram preparadas com lixas de 100 a 1200 mesh e, a seguir, polidas com pasta de diamante de $3 \mu \mathrm{m}$ e $1 \mu \mathrm{m}$. Já a solda foi atacada eletroliticamente por uma solução $10 \%$ de ácido crômico em peso, diluído em água deionizada numa tensão de $2 \mathrm{~V}$ durante $10 \mathrm{~s}$.

O ensaio de microdureza foi realizado com o auxílio da escala Vickers, aplicada uma carga de 0,981 N (100 gf) durante 15 s., conforme norma ASTM E 384 [20]. Foram realizadas cinco indentações por zona de interesse 1, 2, 3 (em P1); 4 (interseção P1/P2); 5, 6, 7 (em P3) e 8 (interseção P3/P4), conforme os passes P1, P2, P3 e P4 do esquema da Figura 4. As indentações espaçadas de 0,1 mm foram realizadas em linha reta no sentido reforço/zona de ligação, passando pelas zonas de interesse. 
A obtenção da diluição foi realizada utilizando as características geométricas das soldas, ou seja, a zona de fusão (ZF) e a zona de reforço (ZR) que compõe o metal de solda. Para o cálculo da diluição foram realizadas as medições em três seções transversais de cada solda, para se calcular o valor médio, sendo utilizada a Equação 2 que representa a expressão matemática da diluição.

$$
D=\frac{Z F}{Z F+Z R} \times 100(\%)
$$

\section{Resultados e Discussão}

\subsection{Soldas de passes isolados}

A Tabela 2 apresenta os resultados da exploração dos parâmetros da soldagem de passes isolados em simples deposição, geometria e diluição das soldas MIG e MIGAF. Nas Figuras 5 e 6, respectivamente, os oscilogramas da tensão e da corrente obtidos das soldagens MIG2 e MIG25AF2 registram variações de até $10 \%$ nos valores da tensão (queda) e da corrente (subida). Neste caso, a inserção do arame frio à poça de fusão certamente afetou as características térmicas, elétricas e magnéticas do arco voltaico original, com influências no seu comportamento operacional. A queda de tensão e o aumento da corrente registrados nos oscilogramas da soldagem MIGAF, representam uma resposta da fonte de energia como compensação à possíveis perturbações no arco voltaico pela introdução do arame frio e, principalmente, no sentido da manutenção do seu comprimento. Este comportamento também ocorreu nas demais condições da soldagem MIGAF deste trabalho, e corrobora os resultados de trabalhos anteriores [15-18].
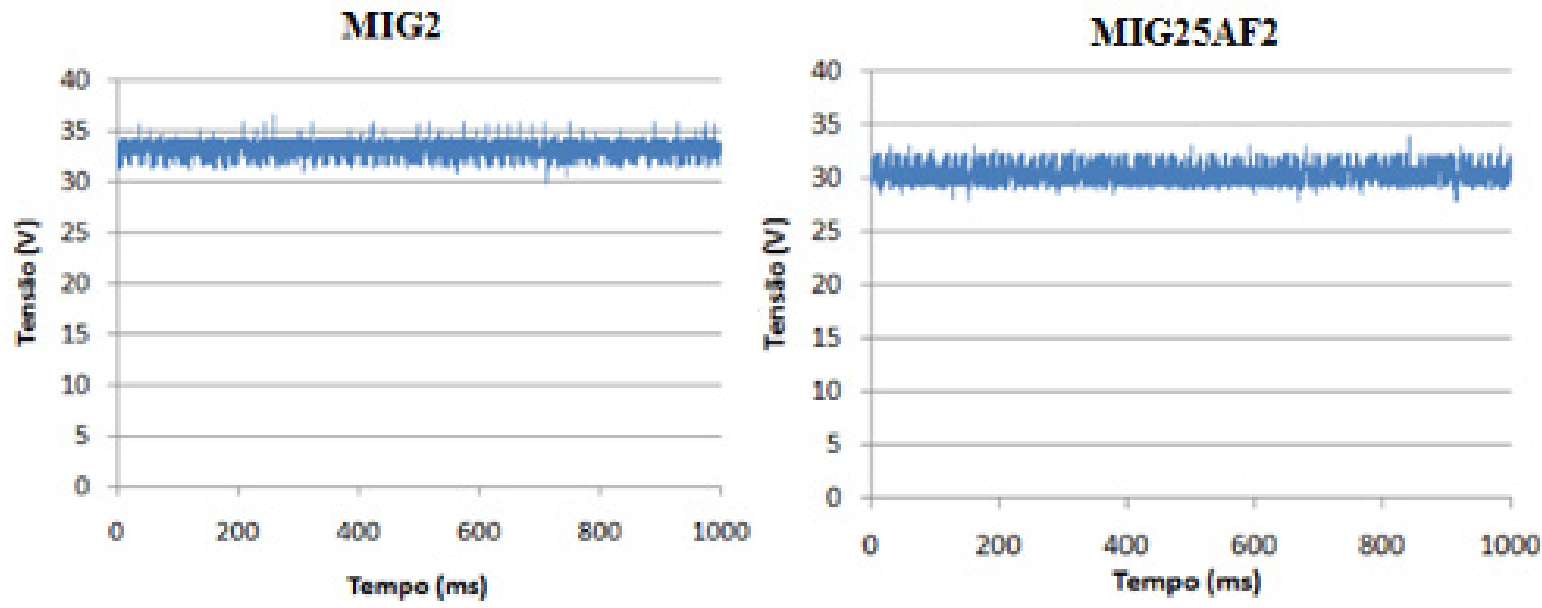

Figura 5. Oscilogramas de tensão. Soldagem MIG2 e MIG25AF2.
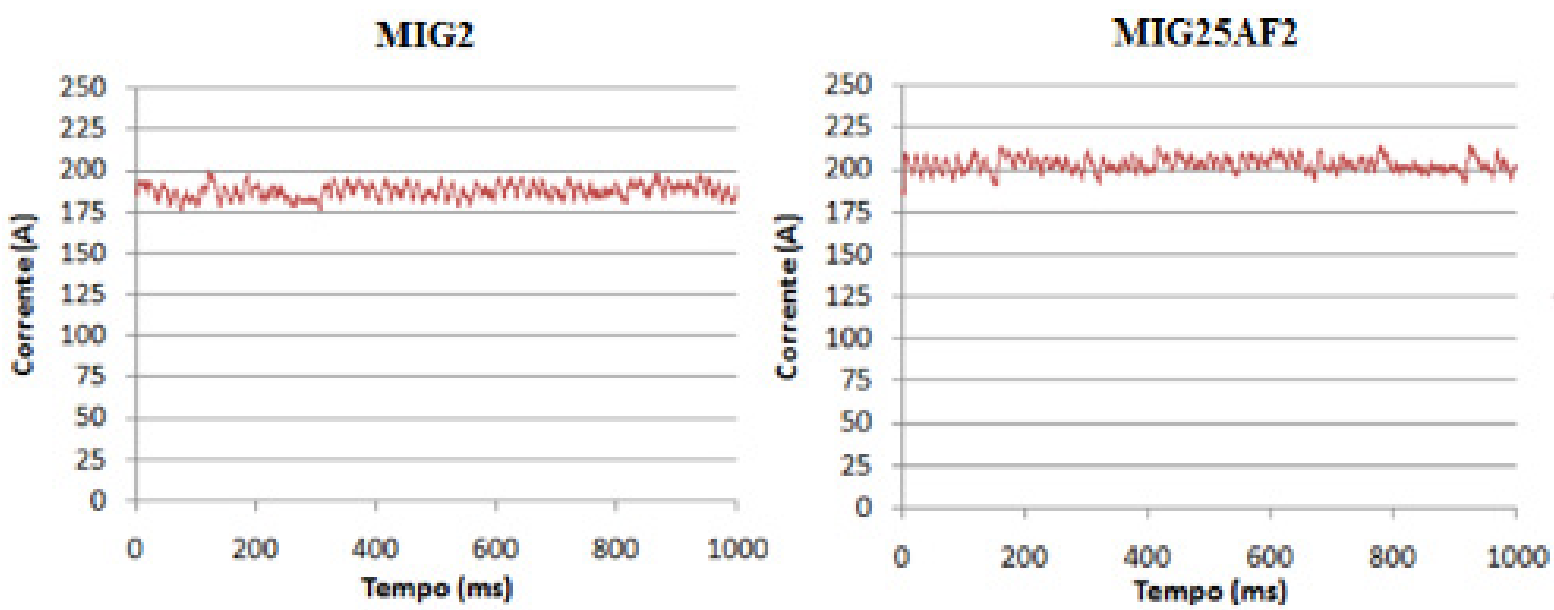

Figura 6. Oscilogramas de corrente. Soldagem MIG2 e MIG25AF2. 
A Figura 7 mostra o aspecto da seção transversal dos passes isolados em simples deposição, com energia $7 \mathrm{~kJ} / \mathrm{cm}$ e variações nas velocidades dos arames eletrodo e frio, conforme dados da Tabela 2. A análise desta figura e do aspecto superficial dos cordões indicou uma regularidade dimensional ao longo do comprimento da solda, ausências de respingos, mordeduras, porosidades e trincas.

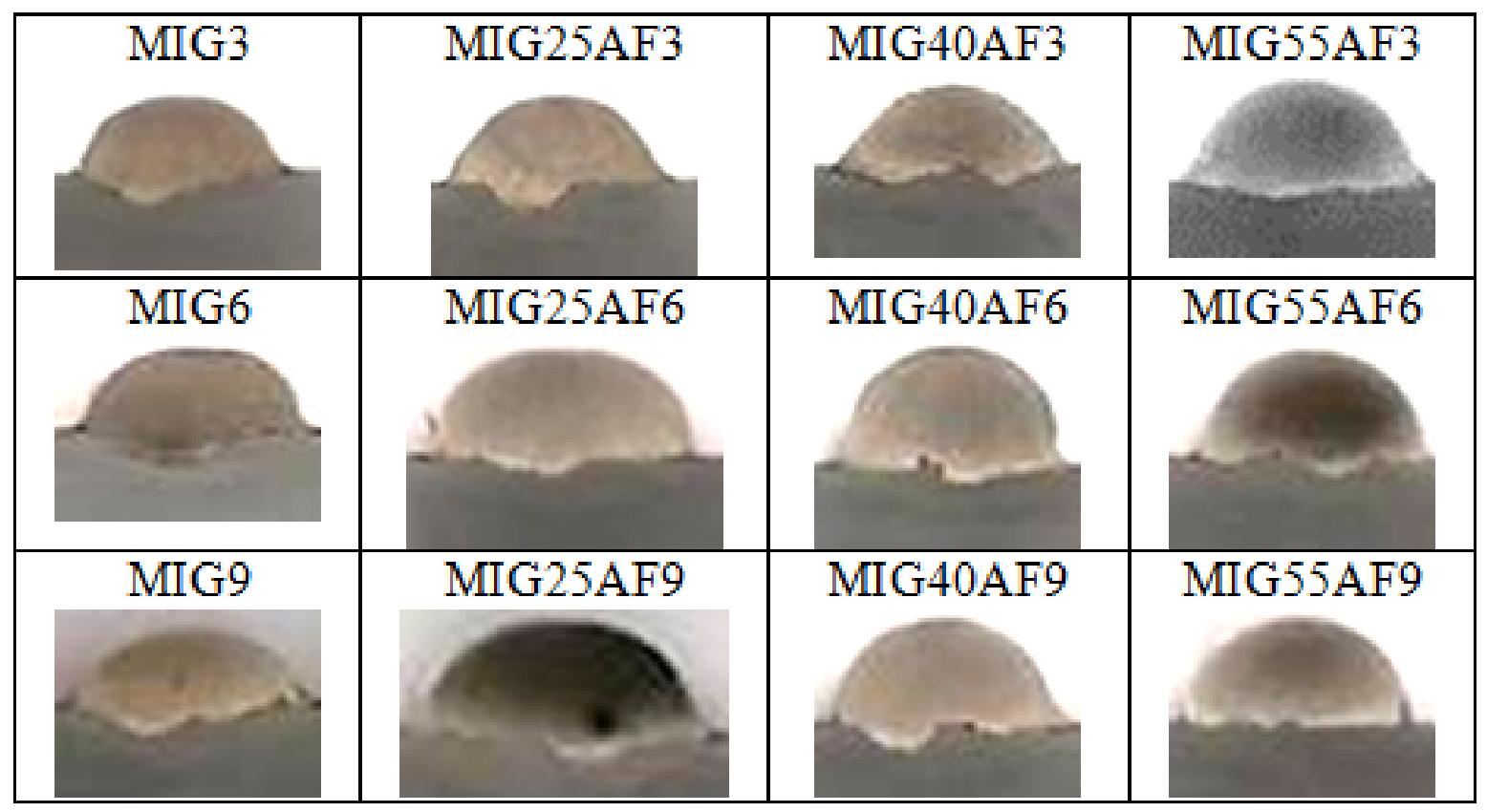

Figura 7. Macrografia da seção transversal das soldas MIG e MIGAF, em passes isolados com 7 kJ/cm.

Pelos resultados apresentados na Tabela 2, mantida constante a velocidade de alimentação de arame, o aumento da energia de soldagem aumentou a taxa de deposição (K) por unidade de comprimento de solda, o reforço e a diluição. A razão $\mathrm{R} / \mathrm{L}$ tendeu a ser maior nas soldas MIGAF, e a crescer com o aumento de $\mathrm{K}$. $\mathrm{O}$ valor de $\mathrm{K}$ foi até $60 \%$ maior para a soldagem MIGAF. Os dados desta tabela são melhor visualizados com o auxílio das Figuras 8, 9, 10 e 11. Na Figura 8 mostra-se a influência da energia de soldagem, nos diferentes níveis da velocidade

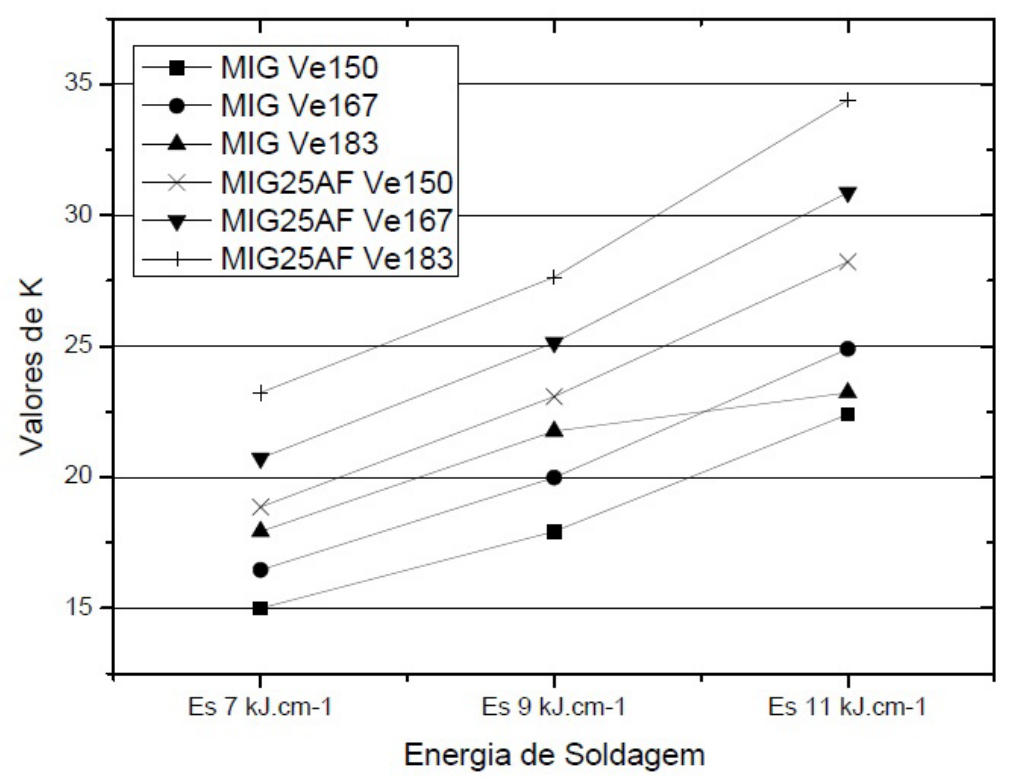

Figura 8. Efeito da energia de soldagem sobre o fator K. Soldagem MIG e MIGAF, para Ve (150, 167 e 183$)$ mm.s-1. 
de arame, sobre o fator K. Os aumentos da energia e da velocidade do arame aumentaram o valor de K, sendo este maior nas soldas MIGAF. A Figura 9 apresenta a variação do reforço em função de K para as soldas MIG e MIG25AF. Nota-se que o critério de aceitação do reforço $(R \geq 4 \mathrm{~mm})$ foi satisfatório nas soldas MIG25AF para $K \geq 23$, e apenas na condição MIG7 para K $\geq 27$,5. A Figura 10 mostra o reforço em função de K para as soldas MIGAF, onde o reforço aumenta com o aumento percentual na adição do arame frio. A Figura 11 indica o efeito da velocidade do arame, nos diferentes níveis da energia de soldagem, sobre a diluição das soldas MIG e MIG25AF. Neste caso, mantida a energia de soldagem a velocidade do arame eletrodo não afetou a diluição. Entretanto, pode-se observar que o aumento percentual na adição do arame frio reduziu a diluição nas soldas MIGAF. Por outro lado, para uma mesma velocidade de arame eletrodo, o aumento da energia de soldagem aumentou a diluição. $\mathrm{O}$ critério menor é melhor para a diluição perseguido para as soldas de revestimento, foi alcançado em sete das quinze condições

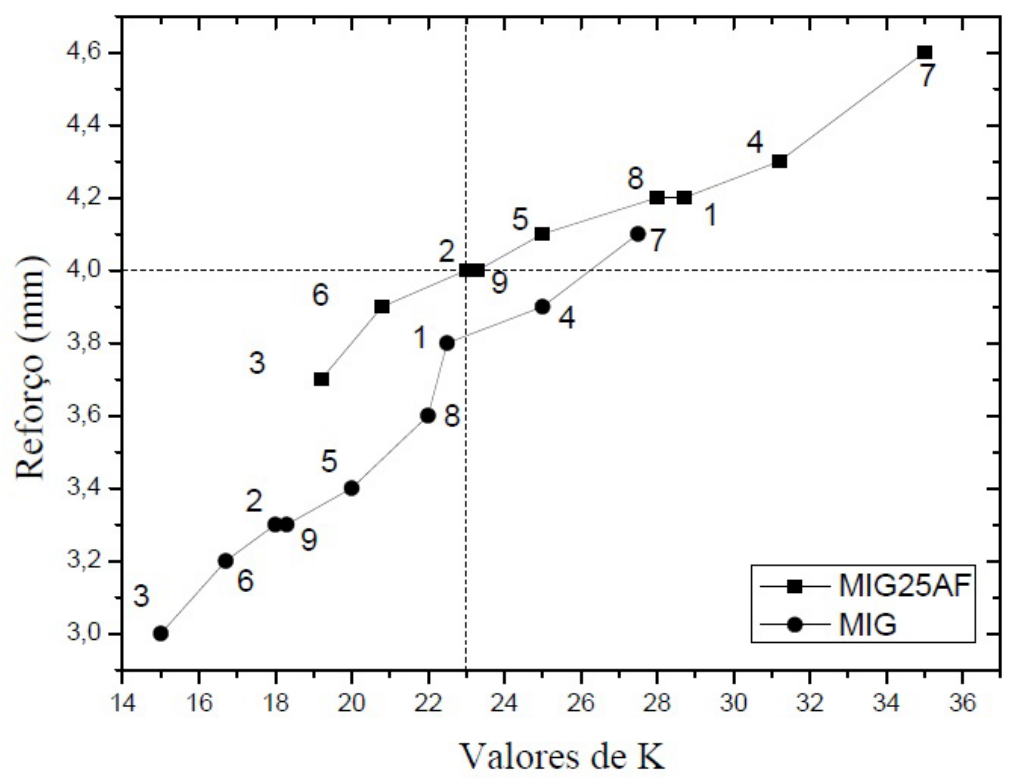

Figura 9. Variação do reforço em função de K. Soldagem MIG1-MIG9 e soldagem MIG25AF1-MIG25AF9.

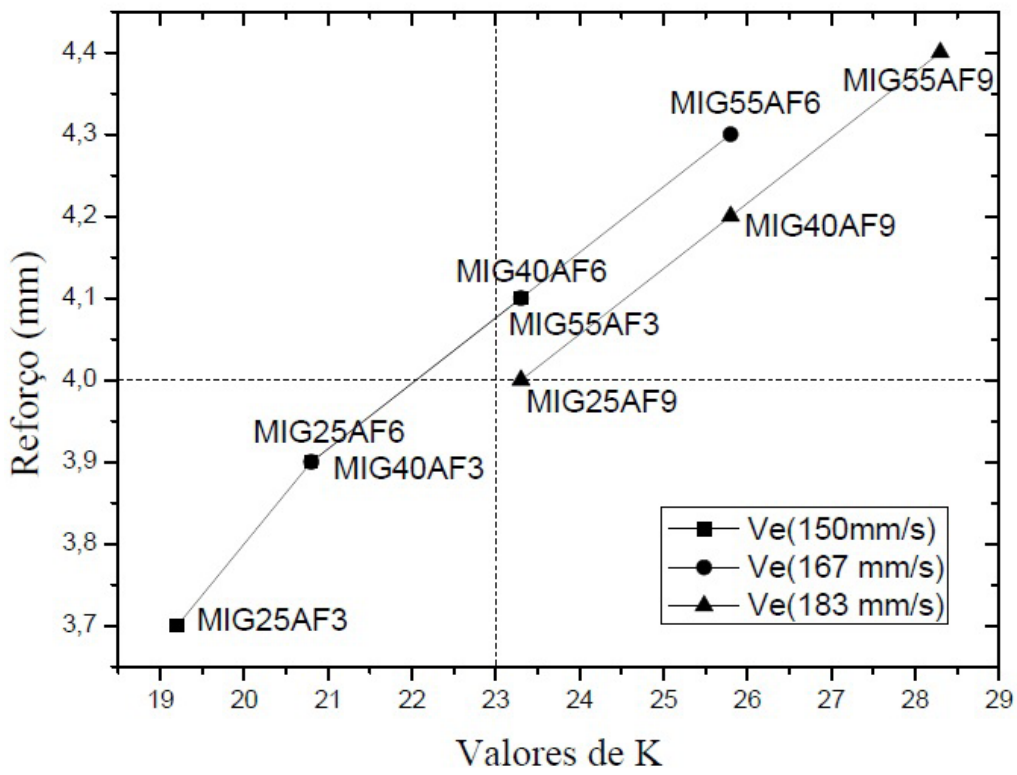

Figura 10. Reforço em função de K para diferentes velocidades de arame. Soldagem MIG25AF3/AF6/AF9, MIG40AF3/ AF6/AF9, MIG55AF3/AF6/AF9. 


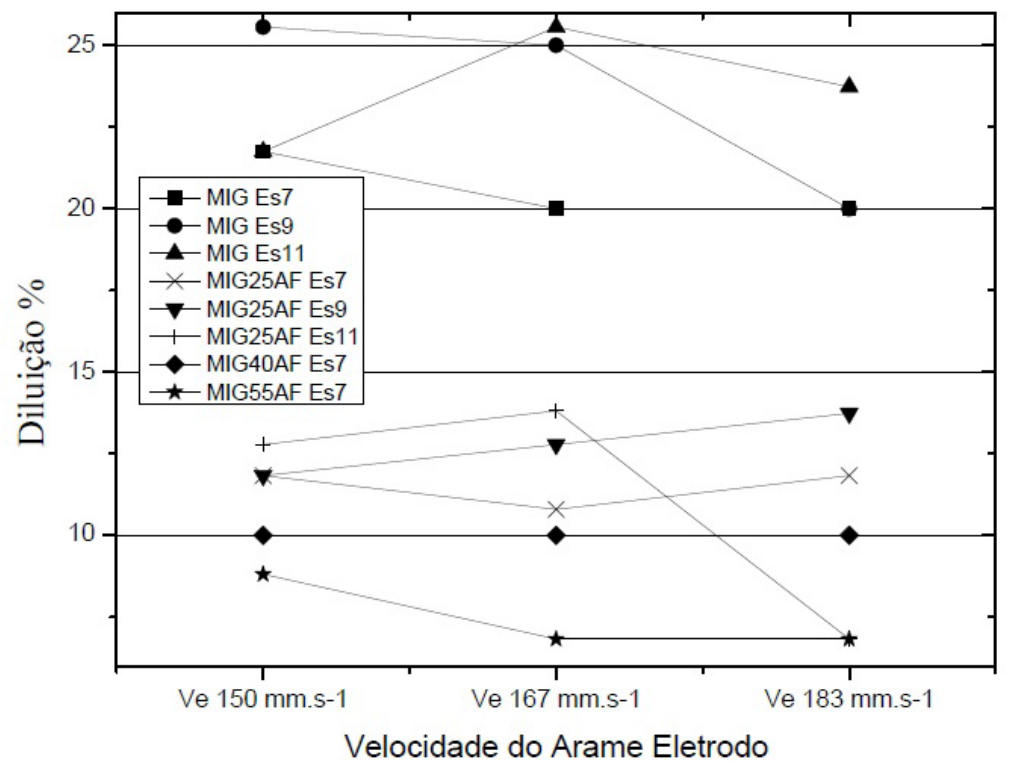

Figura 11. Efeito da velocidade do arame eletrodo sobre a diluição. Soldagem MIG e MIGAF, para Es (7, 9 e 11) kJ.cm-1.

avaliadas na soldagem MIGAF, principalmente naquelas com menor energia de soldagem e maior taxa de adição do arame frio. A diluição se manteve entre 11\% e 14\% nas soldas MIG25AF. Para as soldas MIG a diluição foi mais elevada, entre $20 \%$ e $26 \%$. Deste modo, os valores de diluição foram em média $45 \%$ menor nas soldas MIG25AF, chegando em $60 \%$ de redução na condição MIG25AF2 comparada à solda MIG2. A soldagem MIGAF contemplou a maioria dos critérios de aceitação deste trabalho, a exceção das soldas MIG25AF7, MIG40AF6 e MIG40AF9.

$\mathrm{O}$ atendimento aos critérios do reforço, da relação $\mathrm{R} / \mathrm{L}$ e da diluição conduz a redução do número de passes/camadas para se atingir uma espessura requerida do revestimento com efeitos sobre o custo do projeto, a convexidade, a concentração de tensões, além de defeitos como a falta de fusão. Uma baixa diluição minimiza a possibilidade de contaminação da solda por elementos nocivos difusos do substrato, como o ferro e o carbono. A introdução do arame frio na poça de fusão consome parte do calor para fundir e misturar a massa adicional, com efeitos redutores sobre a intensidade dos movimentos convectivos na poça de fusão e sobre a capacidade de escavar o substrato. Afeta ainda a velocidade de resfriamento com influências sobre o reforço, a diluição e a composição química da solda.

\subsection{Revestimento}

A Figura 12 mostra o aspecto superficial e a macrografia na seção transversal do revestimento MIG25AF7, representativo da qualidade dos demais revestimentos nas condições de soldagem deste trabalho. Na Figura 12a, a boa qualidade obtida no revestimento está associada à estabilidade do arco e a adequada sobreposição lateral dos passes. Assim, o acabamento superficial se apresenta satisfatório com regularidade geométrica planar ao longo da

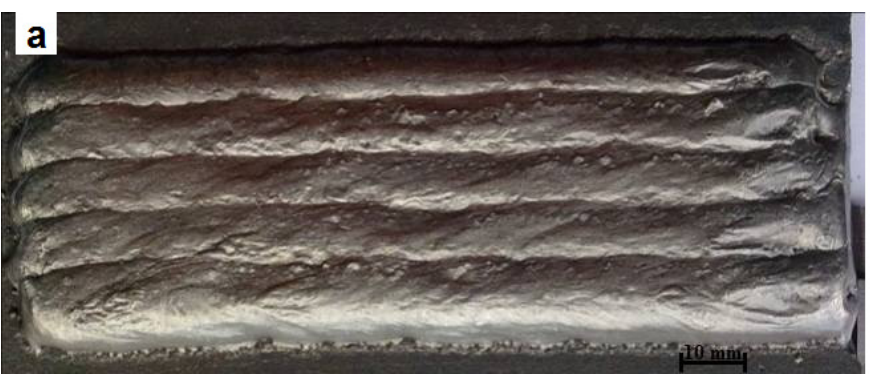

b

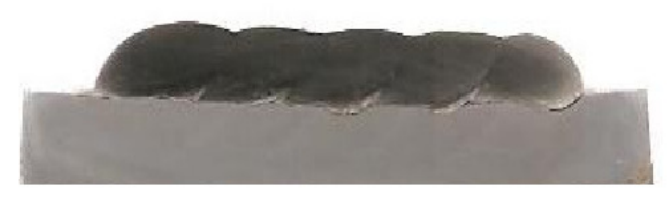

Figura 12. Revestimento MIG25AF7: (a) Aspecto do superficial; (b) Macrografia da seção transversal. 
área revestida, ausência de defeitos e baixa incidência de respingos. A Figura $12 \mathrm{~b}$ mostra a seção transversal deste revestimento, onde não incidem porosidade e falta de fusão entre passes ou entre o revestimento e o substrato.

A Tabela 3 apresenta os dados da diluição dos revestimentos MIG e MIG25AF. Observa-se uma expressiva redução na diluição dos revestimentos MIG25AF comparada aos revestimentos MIG. Mantida constante a energia de soldagem, a diluição do revestimento MIG25AF2 foi até $60 \%$ menor que a diluição do revestimento MIG2. Este comportamento pode ser atribuído dentre outros fatores, ao aumento relativo da massa do metal de adição em composição com o metal de base para a formação da solda. Essa massa adicional em sobreposição na poça de fusão constitui uma maior barreira física, térmica justaposta entre o arco voltaico e o metal de base, com efeitos redutores sobre a intensidade dos movimentos convectivos na poça de fusão, sobre a ação de escavação no substrato e sobre a diluição.

Tabela 3. Diluição dos revestimentos MIG e MIG25AF.

\begin{tabular}{cccc}
\hline Amostra & D (\%) & Amostra & D (\%) \\
MIG1 & 13 & MIG25AF1 & 6,0 \\
MIG2 & 15 & MIG25AF2 & 6,0 \\
MIG3 & 16 & MIG25AF4 & 8,0 \\
MIG5 & 13 & MIG25AF6 & 6,0 \\
MIG6 & 10 & MIG25AF7 & 5,0 \\
MIG8 & 12 & MIG25AF8 & 6,0 \\
\hline
\end{tabular}

As Figuras 13 a 16 mostram as micrografias do terceiro passe dos revestimentos MIG7 e MIG25AF7. A Figura 13 apresenta o aspecto microestrutural próximo à interface metal de solda/substrato. No lado do substrato, pode-se observar uma aparente redução dos grãos da ZACGG para o revestimento MIG25AF7, Figura 13b, comparados aos grãos da ZACGG do revestimento MIG7, Figura 13a. A ZACGG ou ZAC de grãos grosseiros é a região vizinha à zona de ligação que recebeu, no estado sólido, as maiores influências do ciclo térmico de soldagem e, por isso, experimentou um crescimento diferenciado de grãos. Acredita-se que o "roubo" de calor pela adição de arame frio possa ter contribuído para uma diminuição na temperatura sobre a ZACGG, haja vista que o crescimento do grão austenítico está diretamente ligado ao gradiente térmico incidente na região. No lado do metal de solda destacam-se ao longo da interface a formação e o aspecto da zona parcialmente misturada, ZPM, nos revestimentos MIG7, Figura 13a, e MIG25AF7, Figura 13b. A espessura da ZPM tendeu a ser menor no revestimento MIG25AF7.
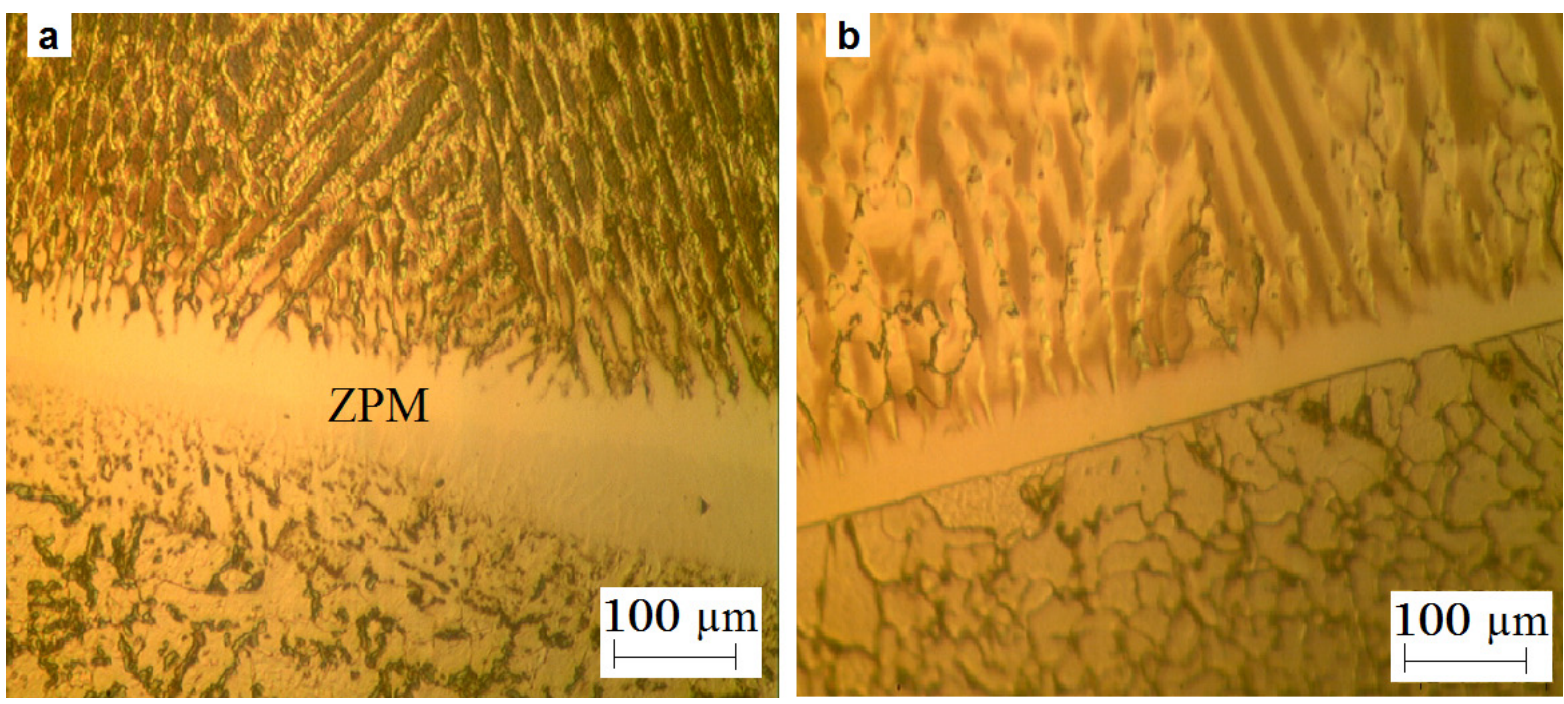

Figura 13. Micrografia na interface solda/substrato no 3o passe do revestimento: (a) Revestimento MIG7; (b) Revestimento MIG25AF7. 
As ZPM são macrossegregações inerentes às soldas dissimilares, cuja composição química e características de resistências diferem daquelas da solda e do substrato, e são propícias à fragilização pela precipitação de carbonetos e formação de estrutura martensítica, dentre outras $[2,7,10]$.

A Figura 14 mostra a estrutura de crescimento colunar dendrítico comum nos revestimentos MIG7 (Figura 14a) e MIG25AF7 (Figura 14b). Existe, no entanto, uma tendência de refinamento na estrutura de solidificação do revestimento MIG25AF7 causado, provavelmente, pelos aumentos nas velocidades de resfriamento e de solidificação. A Figura 15 apresenta o aspecto micrográfico na região de sobreposição do 2ำ para o 3ำ passes (interseção P2/P3), dos revestimentos MIG7 (Figura 15a) e MIG25AF7 (Figura 15b), com destaque ainda para tendência do refinamento na estrutura de solidificação do revestimento MIG25AF7. A Figura 16 mostra o avanço da microestrutura colunar dendrítica caracterizada por taxas de resfriamento mais elevadas, numa região próxima e imediatamente abaixo da superfície do 3o passe (em P3) dos revestimentos MIG7 (Figura 16a) e MIG25AF7 (Figura 16b). A injeção do arame frio na poça de fusão além de desestabilizar a frente de solidificação, conforme já comentado, aumenta a massa metálica na poça de fusão e reduz os movimentos convectivos principalmente nas vizinhanças da zona de
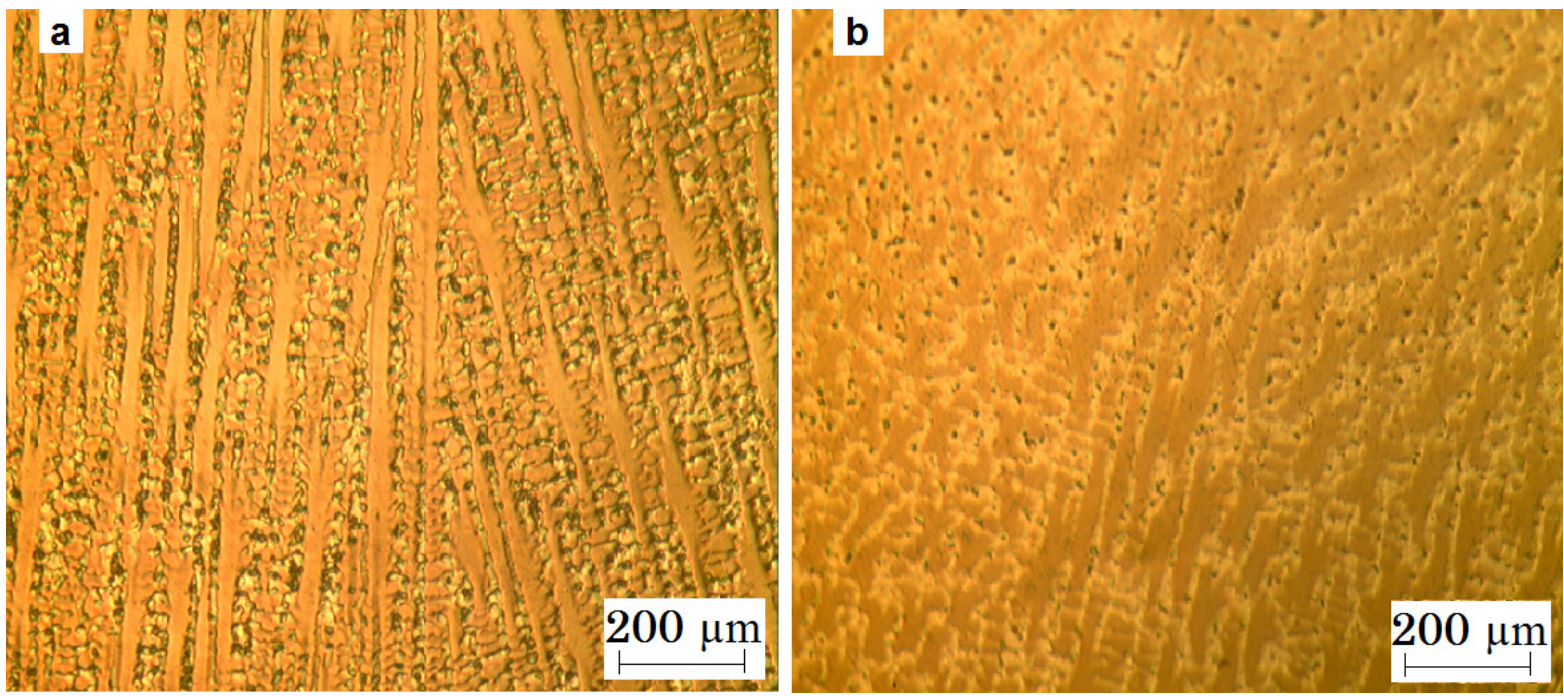

Figura 14. Micrografia do 3 o passe do revestimento, região no centro do passe: (a) Revestimento MIG7; (b) Revestimento MIG25AF7.
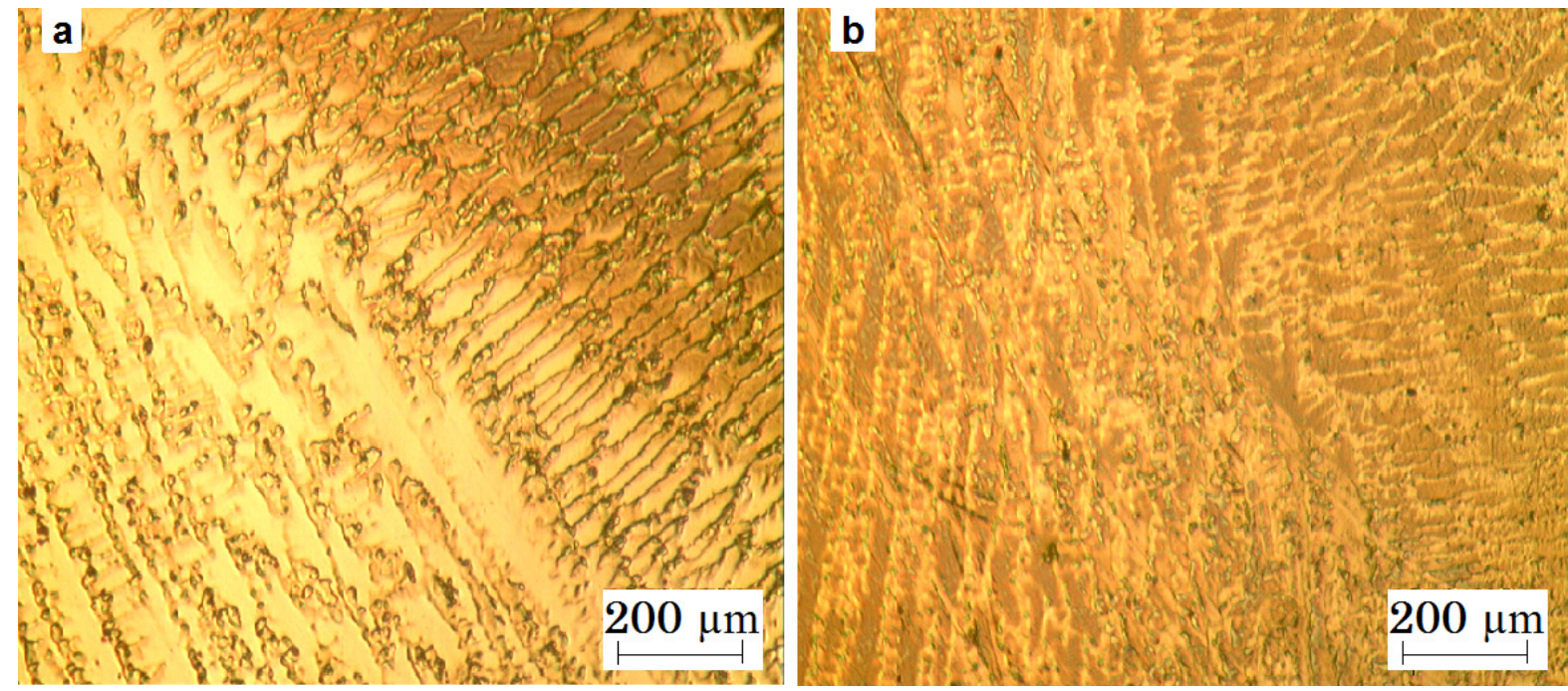

Figura 15. Micrografia na sobreposição do 2ㅇ e 3o passes do revestimento: (a) Revestimento MIG7; (b) Revestimento MIG25AF7. 

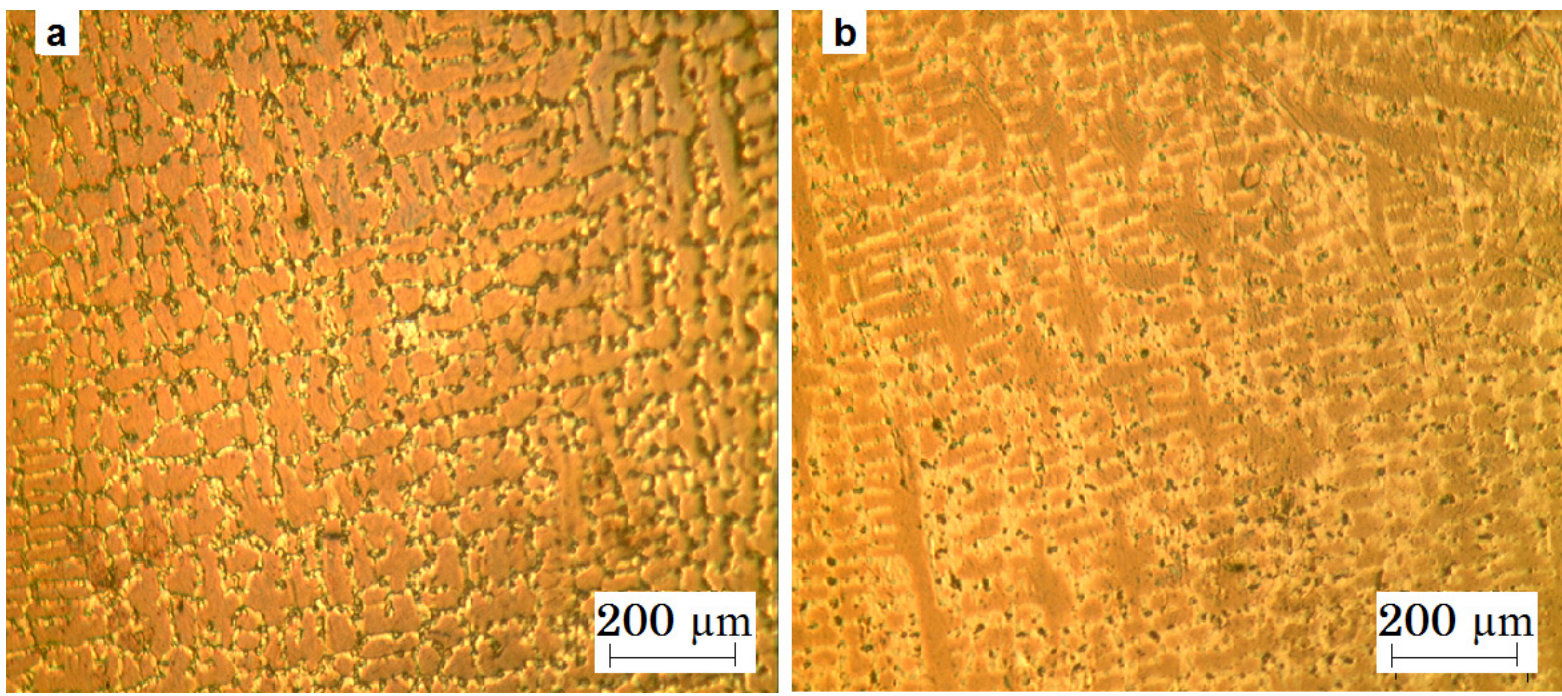

Figura 16. Micrografia do 3을 passe do revestimento, região próxima à face: (a) Revestimento MIG7; (b) Revestimento MIG25AF7.

ligação. Desta forma, fragmentos de dendritas arrancados da interface e arrastados para o centro da poça podem nuclear novos grãos e refinar a estrutura das soldas MIG25AF [2,7,10,19]. Além disso, essas perturbações podem ainda influenciar a espessura fundida do substrato, estagnada junto à interface da zona de ligação, a permanência em altas temperaturas e o tamanho de grãos na ZACGG [19].

As Figuras 17, 18 e 19 apresentam valores de microdureza nas diferentes regiões dos revestimentos MIG e MIGAF. Pela Figura 17, não ocorreram alterações relevantes de microdureza nas amostras analisadas. Foram observadas elevações pontuais da microdureza na ZPM do primeiro passe, provavelmente, devido à precipitação de carbonetos causada pelo enriquecimento de carbono, migrado do substrato na direção do metal de solda.

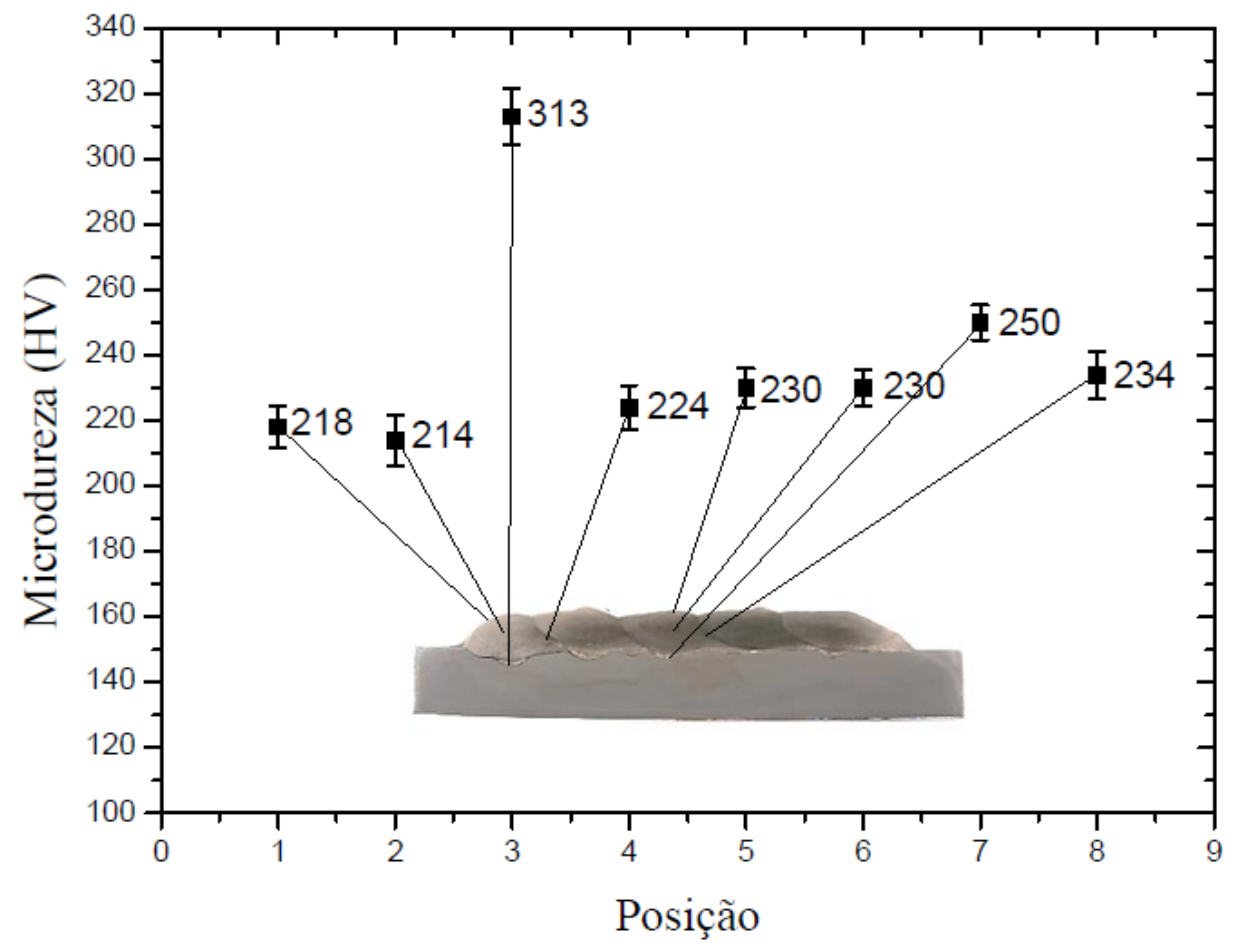

Figura 17. Microdureza em diferentes regiões do revestimento para condição MIG7. 
Revestimento de Níquel Depositado pela Soldagem MIG e MIG com Arame Frio

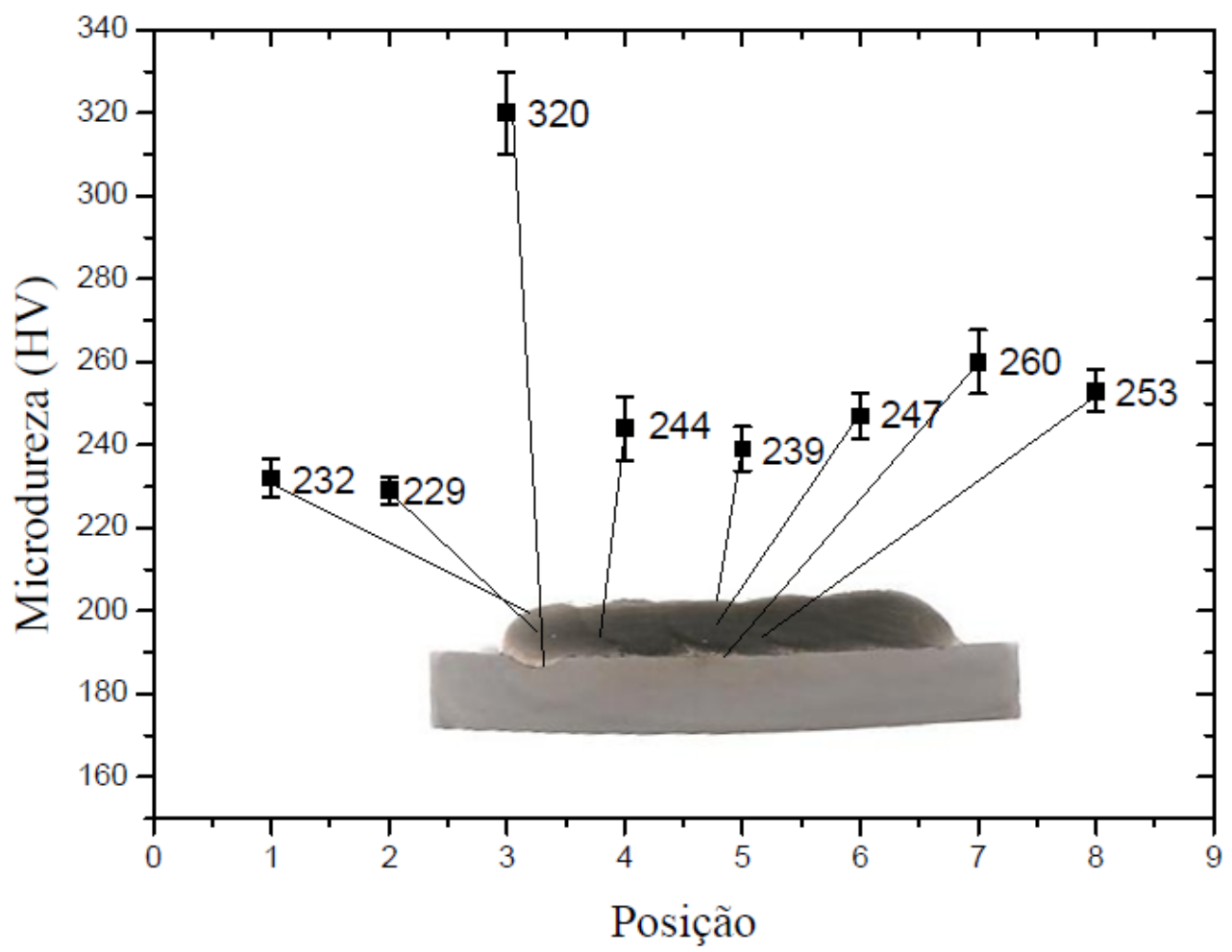

Figura 18. Microdureza em diferentes regiões do revestimento para condição MIG25AF7.

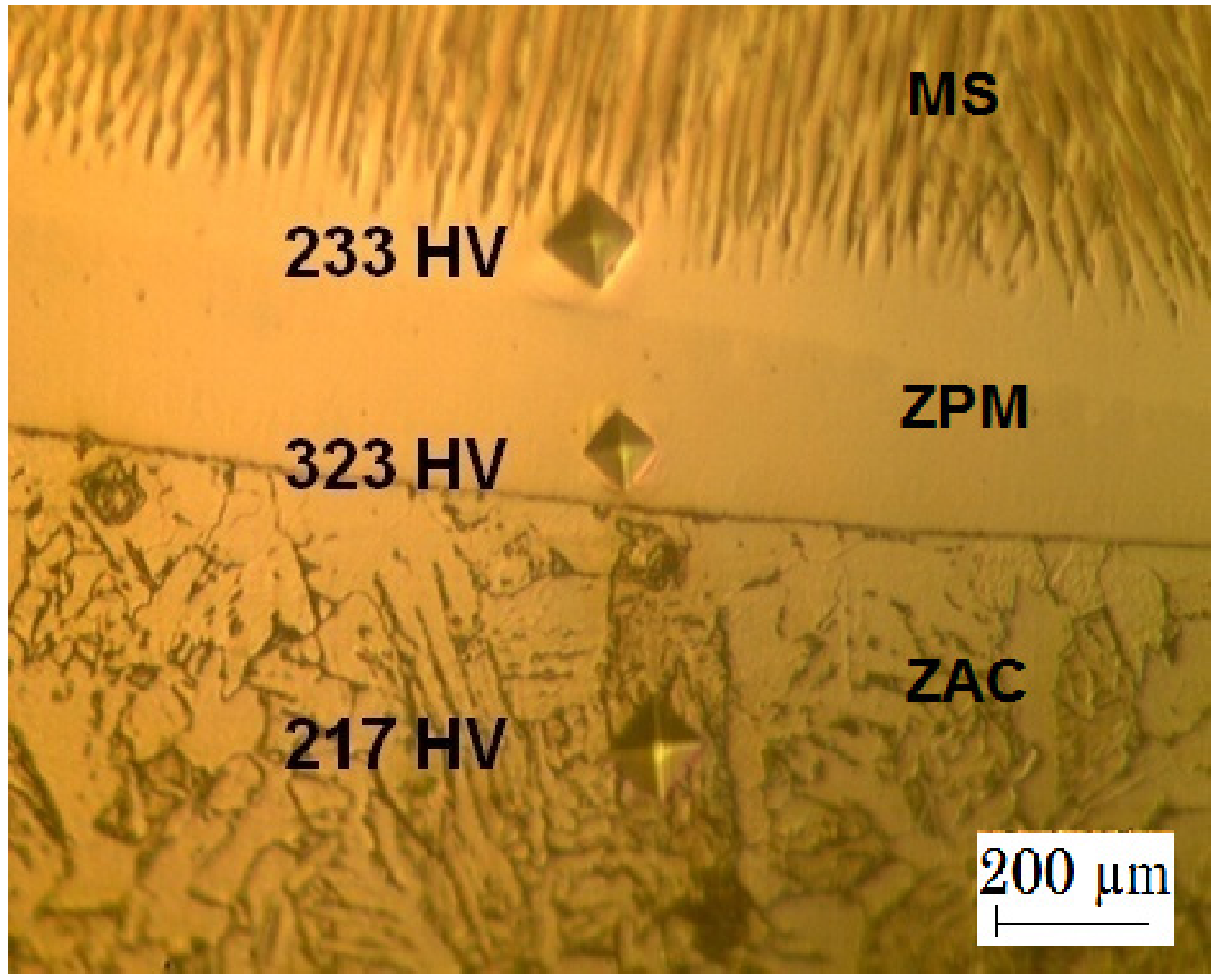

Figura 19. Microdureza na ZAC, ZPM e MS. Revestimento MIG25AF7. 


\section{Conclusões}

A adição do arame frio à poça de fusão não induziu perturbações perceptíveis no arco voltaico e não alterou a qualidade das soldas, na faixa operacional deste trabalho.

$\mathrm{O}$ aumento da energia de soldagem, nos diversos níveis de velocidade de arame, aumentou a diluição e a taxa de deposição $(K)$ por unidade de comprimento de solda, a qual foi até $60 \%$ maior na soldagem MIGAF.

$\mathrm{O}$ aumento de $\mathrm{K}$ reduziu a diluição. O reforço foi maior e a diluição menor nas soldas MIGAF.

$O$ aumento da velocidade do arame eletrodo não influenciou a diluição.

Não foram verificadas alterações microestruturais relevantes entre as soldas MIG e MIGAF.

Os resultados deste trabalho são indicativos do bom desempenho operacional da soldagem MIGAF, como alternativa tecnológica viável para aplicações no campo.

\section{Agradecimentos}

Os autores agradecem a CAPES, CNPq, FINEP, PETROBRÁS/CENPES, REMULT/Núcleo de União e Revestimento de Materiais, FEM/ITEC/UFPA.

\section{Referências}

[1] Kejelin NZ, Buschinelli AJA, Niño CE. Soldagem dissimilar do aço X-60 com Inconel 625. Anais do XXXII CONSOLDA. São Paulo-SP. ABS Associação Brasileira de Soldagem. 2006;01:1-10.

[2] Kou S, Yang K. Fusion-boundary macrosegregation in dissimilarfiller welds. Welding Journal. 2007;86(10):303-312.

[3] Lundin CD. Dissimilar metal welds: transition joints literature review. Welding Journal. 1982;61(2):58-63.

[4] Xavier MD. Mecanismos de endurecimento da superliga inconel 718. Revista Eletrônica de Educação e Tecnologia do SENAI-SP. 2009;3(7):1-11. [acesso em 20 set. 2010]. Disponível em: http:// revistaeletronica.sp.senai.br/index.php/seer/article/viewFile/83/68

[5] Silva CC. Revestimentos de ligas de níquel depositados pelo processo TIG com alimentação de arame frio: aspectos operacionais e metalúrgicos [tese de doutorado]. Fortaleza: Departamento de Engenharia e de Materiais, Universidade Federal do Ceará; 2010.

[6] Mougo AL. Aspectos metalúrgicos da soldagem MIG e MIG derivativa com arame frio em revestimento de chapas planas de aço carbono utilizando uma superliga de níquel [dissertação de mestrado]. Belém: Programa de Pós-graduação em Engenharia Mecânica, Universidade Federal do Pará; 2012.

[7] Doody T. Intermediate mixed zones in dissimilar metal welds for sour service. Welding Journal. 1992;71(3):55-60.

[8] Lima LIL, Silva GM, Chilque ARA, Schvartzman MMMA, Bracarense $A Q$, Quinan MAD. Caracterização microestrutural de soldas dissimilares dos aços ASTM A508 e AISI 316L. Soldagem \& Inspeção. 2010;15(2):112-120.

[9] Lippold JC, Kotecki DJ. Welding metallurgy and weldability of stainless steels. 2. ed. New York: Wiley; 2005. 357 p.

[10] Modenesi PJ. Soldabilidade dos aços inoxidáveis. Osasco: Senai; 2001. 100 p. (Coleção Tecnologia da Soldagem).

[11] Peixoto AL. Caracterização de soldas de revestimentos de aços inoxidável austenítico [dissertação de mestrado]. Belém: Programa de Pós-graduação em Engenharia Mecânica. Universidade Federal do Pará; 2006.

[12] Corrêa CA. Aço inoxidável martensítico aplicado em revestimento pelo processo MIG pulsado e convencional [dissertação de mestrado]. Campinas: Programa de Pós-graduação em Engenharia Mecânica, Universidade Estadual de Campinas; 2000.

[13] Santos DJS. Avaliação do desempenho operacional e metalúrgico do weld overlay de aço inoxidável sobre aço ABNT 1020 [dissertação de mestrado]. Belém: Programa de Pós-graduação em Engenharia Mecânica. Universidade Federal do Pará; 2005.

[14] Quintana FLP. Desempenho do processo MIG-CCEN aplicado à soldagem overlay em aço inoxidável austenítico [dissertação de mestrado]. Belém: Programa de Pós-graduação em Engenharia Mecânica, Universidade Federal do Pará; 2005.

[15] Bacelar ARC, Ferraz AC. Estudo da viabilidade operacional do processo de soldagem MAG com alimentação adicional de um arame frio [trabalho de conclusão de curso]. Belém: Faculdade de Engenharia Mecânica, Universidade Federal do Pará; 2005.

[16] Andrade ESS. Acionamento e controle eletrônico para soldagem GMAW de revestimento interno de dutos com adição de arame frio [dissertação de mestrado]. Belém: Programa de Pós-graduação em Engenharia Mecânica, Universidade Federal do Pará; 2010.

[17] Garcia DN. Soldagem MIG com arame frio aplicada ao revestimento de chapas planas com uma superliga de níquel tipo Hastelloy C-276 [dissertação de mestrado]. Belém: Programa de Pós-graduação em Engenharia Mecânica, Universidade Federal do Pará; 2011.

[18] Sábio AD. Estudo da viabilidade operacional do processo de soldagem MAG com alimentação adicional de arame frio [dissertação de mestrado]. Belém: Programa de Pós-graduação em Engenharia Mecânica, Universidade Federal do Pará; 2007.

[19] Santos MWB. Aspectos metalúrgicos de revestimentos em dutos depositados com a superliga de níquel ERNiCrMo-4 pelos processos MIG convencional e MIG com adição de arame frio [dissertação de mestrado]. Belém: Programa de Pós-graduação em Engenharia Mecânica, Universidade Federal do Pará; 2012.

[20] American Society for Testing And Materials - ASTM. ASTM E384: standard test method for microindentation hardness of materials (Annual Book of ASTM Standards, 03.01). West Conshohocken: ASTM; 2002. 